\title{
El asentamiento romano de Catarroja. Aproximación a su estudio
}

\author{
M. Paz Garcia-Gelabert y M. Garcia Diez
}

\begin{abstract}
RESUMEN
ABSTRACT

Tras la realización de trabajos previos de excavación y de estudio (aún en

su fase previa) en laboratorio, se puede deducir que se han localizado $y$ puesto parcialmente al descubierto los restos de una villa de época romana, con un amplio espectro cronológico (siglo II, hasta al menos el siglo $\mathrm{N}$, con probable ocupación visigoda y tal vez árabe). Se trata de un establecimiento que une la función residencial a la productiva (la villa urbana y la villa rustica de los agrónomos latinos), ubicado en las cercanias del núcleo urbano de mayor importancia de la zona, Valentia. En este trabajo llevamos a cabo una aproximación, aún muy hipotética, al desarrollo de la vida en la villa, y a 10

que pudo ser y representar. basándonos en los textos latinos y en los materiales arqueológicos. El área habitacional y de servicios se After the realization of previous works of excavation and study (yet in previous phase) in laboratory, is possible to infer the localization and put openly (partialy) the rests of an roman villa with a large chronology spectre (second century until, at least, the fourth century with probable visigothic occupation and, maybe, arabian). It is an settement that link the residential function at the profitable one (the villa urbana and the villa rustica of the latin agronomists), located around near the civil nucleus of utmos importance of the zone,

Valentia. Into the work we acomplish an aproximation, yet very hypothetic, at development of the life in the villa and his representation, rest upon the latin texts and in the archaeologist materials. The habitational area and services stay finished with an funeral area, which we also describe.
\end{abstract} completa con un área funeraria, que 


\section{o. INTRODUCCIÓN}

Este estudio gira alrededor de un punto central: los resultados de las prospecciones arqueológicas desarrolladas en el yacimiento de l'Hort de Pepica, Catarroja ${ }^{1}$. Su estudio ha proporcionado - con las debidas precauciones inherentes a que no se ha excavado sistemáticamente ${ }^{2}-$, una villa ${ }^{3}$ romana, con al menos cuatro fases constructivas, cuya cronología indicamos infra. Sería pues, en el sentido amplio del término, un establecimiento, centro de explotación de un fundus, que une a la función residencial, la productiva. Se hallaba al exterior del núcleo urbano más importante del entorno, Valentia - éste probablemente fundado hacia el año 138 a.C. ${ }^{4}-$. El enclave no se opone al concepto de ciudad

El municipio de Catarroja, al sur de Valencia pertenece a la comarca de l'Horta Sud y dentro de ella a la subcomarca l'Horta-Albufera. El núcleo urbano antiguo se asienta sobre un establecimiento árabe, una alquería, que fue conquistado por Jaime I, quien lo donó a Peregrin de Astrosillo. posteriormente pasó a Berenguer Dalmau, el cual le concedió Carta-Puebla en 1355 . "... después pasó a la familia de Calatayud. y Conde del Real: pero hoy lo posee la Marquesa de la Mina..." (B. ESPINALT Y GARCIA, Atlante español o descripción general geográfica, cronológica é histórica de Espana, por reynos, y provincias: de sus ciudades, villas y lugares más famosos: de su población, rios, montes, Madrid, 1784.) ».

? Se halla el yacimiento arqueológico en el extremo norte-noroeste del casco urbano, en la partida del Secanet, en el campo conocido popularmente como l'Hort de Pepica. En el área se encontraban parcelas en las que se cultivaban citricos y productos horticolas. El resto de la superficie estaba colmatado de escombros que rellenaban el vació dejado por las actividades extractivas para fabricar ladrillos. L'Hort de Pepica y el entorno estaban relacionados con el Plan Parcial P.A.U. 2. Chimenea, del Ilmo. Ayuntamiento de Catarroja. Estos planes afectaban directamente a la zona del yacimiento, el cual quedaria cubierto y definitivamente afectado por un nudo de carreteras que habria de circunvalar, en un futuro próximo, la mencionada localidad. Para salvar el yacimiento, nosotros, de conformidad con la Conselleria de Cultura. Educació i Ciencia de la Comunidad de Valencia, y los sres. Alcalde, Concejales de Cultura y Urbanismo y Arquitecto de Catarroja, proyectamos un plan de emergencia, de intervención arqueológica de urgencia (cinco campañas de trabajo de campo. desde septiembre de 1996 a julio de 1997), basado en prospección sistemática por medio de pozos y zanjas de sondeo para delimitar el yacimiento y, en su función, cambiar el plan urbanístico, como asi se llevó a cabo. Hasta que se desarrolle un proyecto integral interdisciplinario, para potenciarlo, el yacimiento, bien delimitado, ha sido nuevamente cubierto con tierra, debidamente protegidas sus estructuras con red. Iona y arena fina.

3 El término villa comprende un concepto muy amplio. Desde luego, y según la mayoría de los autores latinos es todo edificio aislado situado en el campo, y con numerosas dependencias rústicas y nobles, aunque se pueden asimilar al mismo numerosas funcionalidades. Remitimos para una mayor definición y comprensión del concepto a S. AGACHE. L'idee de villa dans la littérature latine, Thése de lllème cycle, Paris-Nanterre, 1981. R. MARTin, Recherches sur les agronomes latins, Paris, 1971.

" T. LIVIO (per.LV) escribe: "lunius Brutus cos. in Hispania is. qui sub Viriatho militaverant. agros et oppidum dedit, quod vocatum est Valentia". este evento tendria lugar hacia el 138 a.C. Sobre la localización de esta fundación existen numerosas controversias. Epigráficamente se documenta como colonia la Valentia que ha dado lugar a la ciudad de Valencia a partir de sigto I. 
sino que lo complementa. Estaba situado en el área de influencia de Valentia y las aportaciones serían mútuas: el enriquecimiento del campo vertiria sobre los grupos urbanos dominantes que, al mismo tiempo permitirian un desarrollo superior del medio rural en materia económica y cultural 5 .

Los hallazgos, especificados en el apartado IV, documentados en el yacimiento de l'Hort de Pepica, que nos han Ilevado a esta conclusión, responden, en efecto, a la doble vertiente habitacional y de producción ${ }^{6}$.

Ahora bien, no trataremos, salvo alguna explicación indispensable, sobre métodos de trabajo de campo, ni sobre definición estructural interna de los materiales encontrados en el transcurso de la investigación ${ }^{7}$. En este último aspecto, como argumenta K.C. Chang ${ }^{8}$ : "Un asentamiento arqueológico puede muy bien ser exactamente idéntico a un conjunto de artefactos estructurado y situado en un contexto de forma semejante, pero no es sin más cualquier agregado de artefactos". Así pues, nuestra idea, que también refleja Chang ${ }^{9}$, es intentar articular dichos artefactos con el hombre que los adquirió y/o construyó, utilizó y disfrutó. Es decir con el hombre que vivió en las edificaciones, cuyos cimientos, arrasados, documentamos. $Y$, sobre todo, en el caso del yacimiento de l'Hort de Pepica, con las actividades laborales de esclavos ${ }^{10} \mathrm{o}$ colonos (según las épocas, teniendo en cuenta la larga existencia de la villa) empleados por el dominus, si lo hubo, para el cultivo de las tierras o el cuidado del ganado. Asi pues procuraremos revivir las actividades cotidianas en un entorno campestre, aunque los resultados, en definitiva, son desalentadores, siempre lo son, debido a la insuficiencia de unos datos y a la falta o repetición de otros.

N. MORERe, Las villas romanas en la Galia Narbonense. Madrid, 1989, pág. 10.

Columena (r.r. I, VI) escribe que los romanos dividían sus establecimietnos agricolas y ganaderos en tres partes una que denominaban villa rustica, destinada a las faenas del campo, y comprendía las viviendas de los sirvientes, los corrales, los establos, y los cobertizos; otra denominada villa fructuaria, servia para guardar las cosechas y comprendia graneros, bodegas, lagares, prensas, etc., y la tercera llamada villa urbana, reservada para la morada del dueño y de la familia. Sobre la organización de las villae, también Catón (De agr. III y IV).

Quedan reflejados en la memoria preliminar de excavación que se ha de presentar, en cumplimiento de la orden del 31 de julio de 1987. de la Conselleria de Cultura. Educació i Ciencia. por la cual se regula la realización de actividades arqueológicas en la Comunitat de València

\& Nuevas perspectivas en arqueologia, Madrid, 1977, pág. 65

9 Nuevas perspectivas... págs. 50-53, 65-66.

10 Los esclavos en las fincas rústicas romanas se encargaban de todo tipo de trabajos bajo la vigilancia de los villici. Las condiciones de los esclavos durante la Republica eran inhumanas; a partir de la lex Petronia, y durante todo el Imperio, se suavizaron sus condiciones de vida, cf. J. CARCOPINO. La vie quotidienne à Rome à l'apogee de l'Empire. Paris. 1939. pags. 76-78. 


\section{ROMA Y LA TRADICIÓN AGRICOLA}

Como idea preliminar en el estudio del yacimiento y de las funcionalidades inherentes a los rasgos encontrados, hemos caido en la tentación de hacer un breve inciso acerca de la mentalidad primordial romana, que impulsó la colonización agrícola, desde luego basada en el lucro, pero también en su remota tradición campesina. La misma se ha de hacer pasar a los territorios conquistados, porque fueron explotados por ellos (o por itálicos). Y así contemplamos como el campo, los productos generados de su cultivo, constituyeron en Roma, desde su génesis, el más importante factor de rendimiento en la economía, agrícola en sus más hondas raíces. Por esta causa, porque el romano, desde las élites a los estratos sociales más bajos, siempre estuvo muy apegado a la tierra, es por lo que en mosaicos, pinturas parietales, relieves, y en cualquier objeto relacionado con el arte y la artesanía, no es raro contemplar figuraciones íntimamente conexionadas con el mundo rural en sus múltiples y variadas facetas. También los autores greco-latinos trataron a menudo cuestiones agricolas. ganaderas, o temas asociados. En todos estos documentos ha quedado bien reflejada la vida enraizada en la tierra, en la naturaleza ${ }^{11}$. Para no dilatarnos excesivamente en entrar en materia, sólo espigamos la mentalidad de científicos y literatos ${ }^{12}$, que vivieron en la denominada Edad de Oro de las letras latinas, durante el Principado. En esta fase histórica la oposición campo-ciudad aparecía ya claramente decidida, y se sentía la añoranza de las realidades campestres que hicieron la grandeza de Italia, nostalgia de aquel verum et barbarum rus al que alude Marcial (III, 58, 5), nostalgia de los viejos campesinos romanos, cuyo ejemplo sería siempre invocado y que fundaron el mos maiorum. $Y$ contemplamos a Sexto Pom-

Cf. M.P. Garcia-Gelabert, El carro como transporte agricola en mosaicos y otras figuraciones plásticas de Roma y sus provincias del ámbito mediterráneo. L'Africa romana. Atti dell XI convegno di studio (Cartagine, 1994), Sassari, 1996, pags. 529-554. Aunque se presta, sobre todo, atención al transporte agrícola, se hace alusión a variadas actividades rústicas.

Estos personajes en general se hallaban muy cerca de la Corte, y en los escritos hacen referencia a una realidad agricola basada en el latifundio. Sus enseñanzas acerca de la construcción de villae rurales, con numerosas dependencias de todo tipo no tuvieron, con seguridad nada que ver con la realidad de las granjas, alquerias, de los pequeños propietarios, deprimidos, con una economia de subsistencia precaria. Ese mundo en la ciencia arqueológica se nos escapa. Nuestra experiencia nos dicta que de la vida del romano, itálico, etc., que compone la base de la pirámide social, apenas ha llegado a nuestra época una tierra cenicienta, con numerosos restos de materia orgánica (de las viviendas peremnes, resíduos de hogares, de cereales y otros), algun zócalo de mamposteria a hueso, y fragmentos de vasijas de cocina. A lo más algún vestigio metálico. Para el estudio de las villae que los arqueólogos solemos excavar. es decir con una cierta prestancia (por los materiales de construcción y muebles hallados), son válidas las obras de los cientificos a los que haremos reterencia. 
peyo bloqueando las costas de Italia e impidiendo el aprovechamiento de cereales; y a Antonio, en Oriente, que detenía la afluencia de oro. Para vivir era necesario volver a los principios de la economía esencialmente agrícola del pasado ${ }^{13}$, en cierta manera parcialmente abandonada, al menos físicamente, por las élites ciudadanas. De hecho Varrón (r.r. III, II, 6) denuncia este fenómeno, es decir la ruptura espacial campo/ciudad: "¿Qué tiene de común vuestra casa de campo con las que poseian tu abuelo y tu bisabuelo?». Asi pues la politica de Augusto aprovechaba esta oportunidad para restaurar en el alma romana las antiguas virtudes del pueblo y especialmente el gusto por la agricultura.

Virgilio, que había seguido manteniéndose rústico, tanto en los gustos como en las maneras, y sentía palpitar la tierra, se asoció a esta realidad animada por la ciencia. Marco Terencio Varrón y Julio Higinio, publicaron sendos tratados de agricultura. Ellos ejercieron su influencia sobre Virgilio, junto con autores griegos como Hesiodo, Aristóteles, Teofrasto, Eratóstenes de Cirene, Arato y Nicandro de Colofon, y latinos como Marco Porcio Catón. Y cantó la gloria y el libre gozo del campo, el intimo contacto con la tierra.

En las Geórgicas, glosa, en los cuatro cantos, con vigorosos acentos la alabanza de la vida del labrador ${ }^{14}$. Otros como Lucrecio, los elegíacos, y Horacio ${ }^{15}$, celebraron la vida rústica, y bajo la influencia de un epicureísmo o de un estoicismo adaptados, consideraban que la felicidad más depurada consistia en hallarse al margen de la vida pública. Incluso el tratadista de Arquitectura, Vitruvio, en De Architectura - estudio dividido en diez libros-, relaciona, en el libro VI, cómo, de qué manera y con qué, han de construirse y acondicionarse las casas de campo y la distribución de sus dependencias ${ }^{16}$. Con anterioridad existieron prestigiosos políticos y científicos que, asimismo, colocaron su acento en el campo, en su explotación, y elogiaron sus excelencias, como es el caso, entre otros, de Catón, que como político representó las tendencias de dominio de los círculos esclavistas de Roma, y como erudito publicó un tratado que engloba medicina, retórica, agricultura, inspirado en el estoicismo más intransigente; o Varrón, en su estudio sobre

\footnotetext{
A. GRENIER. El genio romano en la religión, en el pensamiento y en el arte, Barcelona, 1927. pág. 376 .

Contenido de los cantos: I. El campo. II. Los árboles. con su célebre elogio de la vida campestre (458-542), algunos de cuyos párratos espigamos: “ ¡Oh, demasiado felices los labradores si conocieran los bienes de que gozan !»... «El labrador ara la tierra con la corva reja. Este es su trabajo de todo el año: con él sostiene a su patria y a sus pequeñuelos hijos, a sus ganados y a sus yuntas, que lo merecen bien...". III. Los animales. IV. Las abejas. alma".

Con respecto a Virgilio escribe Horacio (Carm. I, 3, 1-8) "su amigo querido, mitad de su

También en el libro VII.
} 
temas agricolas y ganaderos, De re rustica ${ }^{17}$, destacable por su rigor de sistematización y de método. $Y$ también con posterioridad al momento que hemos determinado como comienzo de esta disertación, se cuentan eminentes personajes de ciencia, tal cuales son el científico y agrónomo Columela (De re rustica) ${ }^{18}$; o Plinio el Viejo quien en Naturalis Historia -verdadera enciclopedia -, hace frecuentes alusiones al mundo vegetal y al animal, fundamentadas, sobre todo, en estudios recopilados de los sabios que le antecedieron ${ }^{19}$; o Paladio, que con su Opus Agriculturae (13 libros), heredera de una larga tradición griega, latina y cartaginesa, cierra la larga serie de tratados sobre agricultura que en Roma habia iniciado Catón.

De ellos y de otros no citados, se pueden extraer, además de la mentalidad romana que se acerca a la naturaleza, aplicada a los beneficios humanos, útiles datos para la interpretación de las explotaciones agrícolas romanas en Italia, o en los territorios dominados, en este caso para el asentamiento de l'Hort de Pepica. Y es más, en este estudio, vamos en pos de sus pasos, sobre todo de los de Varrón y Columela, aunque podríamos ir tras los de cualesquiera otros agrónomos, pues todos ellos derivan a la misma técnica expositiva.

\section{ARTICULACIÓN DE LA VILLA DE CATARROJA CON EL ENTORNO}

Concomitante con la fundación de Valentia, paulatinamente irían apareciendo numerosas células de producción agrícola y ganadera, tal vez explotadas por soldados veteranos, de la misma procedencia que los que poblaron aquélla. E. Pingarrón ${ }^{20}$ en la zona meridional de la comarca de l'Horta Sud, ha creido ver una centuriatio, racionalmente contenida en el ager Valentinus, y en la cual estaría incluida la villa en estudio. Según dicha autora: "...la carretera $\mathrm{N}-340$ constituye el cardo maximus del sistema, comenzando las coincidencias métricas a partir de Benetússer hacia el sur... El límite meridional vendría dado por una línea ideal que uniera la parte sur de las localidades de Silla y Alcásser, pero es posible que aún

17 La obra consta de tres libros, I. Agricultura. II. Ganaderia. III. Cuidados de la granja.

18 Estructurada en doce libros.

19 Aparte de lo que debe a los resultados de su experiencia y de su observación, que parece ser no fue mucho, la obra de Plinio se compuso sobre multitud de notas y extractos que fue acumulando a lo largo de su vida. En las notas anotaba el autor todo cuanto recopilaba. Sabemos que consultó 146 autores latinos y 327 griegos, en su mayoría.

20 Rastreo de una centuriatio en la zona sur de la Huerta de Valencia, Saitabi 31, 1981, págs. 149-165. 
continuara a lo largo de una centuria más» ${ }^{21}$. Y es de la opinión que el cardo maximus sería la Vía Augusta ${ }^{22}$.

Como es sobradamente conocido, cualquier centuriatio supone un reparto de tierras a un número, no detallado de colonos, conllevando la inexistencia de la gran propiedad. Así pues, si partimos de la teoría de Pingarrón de que en el área de su trabajo los agrimensores romanos determinaron una centuriatio, las tierras que pudo comprender la villa de Catarroja no serian muy numerosas, es más, no podríamos ni tan siquiera denominarla villa, tal como entendemos el término ${ }^{23}$. Formaría parte de un poblamiento de pequeñas agrupaciones de población, aldeas (vicl). Mas esto no lo documentamos bajo ningún aspecto en el paraje investigado. Al contrario, el hábitat era disperso y compuesto probablemente de villae ${ }^{24}$. Cada una de ellas abarcaría un area de explotación, acerca de todas y cada una de las cuales no tenemos suficiente base documental. Cuando concluyamos los estudios previstos, es decir las prospecciones sistemáticas de superficie del entorno, será posible, siempre con un margen de duda razonable, aclarar el patrón de asentamiento, en el periodo de tiempo comprendido entre los siglos I-IV, ambos inclusive. Bien, por tanto, en el caso de que nos encontráramos en un territorio centurial, la aparición de las villae debió corresponder a procesos posteriores de aglutinamiento de la propiedad, por causas varias ${ }^{25}$.

\section{SITUACIÓN DE LA VILLA}

Se encuentra en la parte alta del pueblo. Se trata de una suave elevación y por tanto la más salubre en la época en que se hallaban en funcio-

21 E. Pingarron, Rastreo de una centuriatio..., pág. 152. Sobre centuriationes en España, cf. VV.AA., Estudios sobre centuriaciones romanas en España, Madrid, 1974.

22 E. Pingarrón, Rastreo de una centuriatio... págs. 154-157. La localización de la Via Augusta por la Comarca de l'Horta Sud aún se halla en estudio, esbozándose abundantes opiniones, más o menos fundamentadas. De momento, y hasta que no trabajemos más a fondo el patrón de asentamiento del entorno, nos abstenemos de dar nuestra opinión. Existiendo numerosos trabajos sobre el sistema viario romano, remitimos a una publicación reciente, que además de tratar el mismo con rigor cientifico y específicamente para la Comunidad Valenciana, comprende un amplio repertorio bibliográfico: F. Arasa, V.M. Rossello, Les vies romanes del territori Valencià, València, 1995

23 Vid. nota 3.

24 Probables vestigios de villae de época imperial se han hallado en: término de Silla, al noreste de la población hay una zona de yacimiento en torno al Mas de Baix, partida de l'Alter. Término de Alcasser, se halló un tesorillo bizantino. Además se han reconocido en los alrededores de la población vestigios romanos altoimperiales. Término de Catarroja, en las inmediaciones del yacimiento por nosotros estudiado, aproximadamente a dos kilómetros al sur, hemos hallado restos de otro hábitat similar al de la partida de Salt del Llop.

25 E. Pingarron, Rastreo de una centuriatio..., pag. 159 
namiento las instalaciones, y también la más defendida de las avenidas de agua, dentro de la precariedad de defensa que puede conllevar tan escasa altitud (Columela, r.r. I, IV «...ha de ser en un sitio un poco más elevado que lo demás del terreno, no sea que si baja un torrente formado por las lluvias de lo alto de la colina, conmueva los cimientos de la casa"). La elevación sobre el nivel del mar es mínima, ya que Catarroja está situada a $9 \mathrm{~m}$., siendo la altitud más importante de $16 \mathrm{~m}$. De lo que no cabe duda es que el caserio, o una porción, fue cubierto por el agua o sufrió algún tipo de avatar, relacionado con fuertes lluvias. Para esta afirmación nos basamos en la presencia de potentes niveles de inundación en los estratos altoimperiales. Las aguas pluviales, por la experiencia de riadas modernas, pueden lievar por delante huertas, con árboles y tapias y todo lo que entrillan. Otro factor de peligro a tener en cuenta fueron las aguas de la Albufera. Paulatinamente se han ido retirando, debido en parte a la aportación de tierras aluvionales, en parte a la desecación natural consecuente con un clima menos húmedo, y en parte a la acción antrópica. Asi pues aunque el eje norte-sur es el que ha sufrido mayor reducción, hace aproximadamente dos mil años sus riberas no se hallarían muy lejanas de la villa. En el lugar en el que fundaron la villa, destacando sobre el llano, los vientos, sobre todo el de levante, debieron hacer la atmósfera más limpia, llevándose las exhalaciones de las aguas pantanosas hacia otras áreas. De todas formas, el paisaje debió remitirse a una llanura cubierta de cenagales, insaluble, que se haría habitable gracias al tesón ingeniero de los romanos. En los comienzos de la colonización romana la puesta en valor de tales parajes hubo de exigir un considerable esfuerzo para los recien llegados (no hay vestigios ocupacionales de grupos autóctonos), pero muy rentable, sobre todo teniendo en cuenta la cercanía del asentamiento urbano de Valentia (Columela, r.r. I, II: "Soy, pues, de opinión de que la hacienda que se compre esté cerca de la ciudad...") y la feracidad de la tierra. Pero la insalubridad ambiental haria que, no obstante los esfuerzos, la vida fuera difícil, y sobre todo en época cálida, con los vapores producidos por la evaporación del agua estancada, con miríadas de insectos, propagadores de enfermedades para hombres y animales, produciendo una mortandad considerable ${ }^{26}$, etc.

La granja se sitúa en un frente arcilloso, cercano a dos cursos hídricos de importancia, además de otros de menor consideración, por lo cual no

26 En esta zona las fundaciones de hábitats no siguieron las precisiones de los hombres de ciencia antiguos, que propugnan para la ubicación de las viviendas, de las granjas, un clima saludable (Columela, r.r. I, II, IV. Vitruvio, I. IV; VI, IX. Paladio, Op. agric. I, XVI)). Primó la fertilidad de la tierra, y no hay que perder de vista las potencialidades pesqueras de la Albutera y la tan repetida cercania a Valentia. 
tenía problemas de abastecimiento (Columela, r.r. I, II: «También es necesario un nacimiento de agua, de donde se saquen acequias que rieguen los prados, los huertos...."; Varrón, r.r. I, XI,2). Uno es el barranco de Torrent o de Xiva, límite natural por el noreste con Masanasa, y que desagua en la Albufera. En la actualidad no tiene un regimen constante de agua. Ordinariamente se encuentra con un caudal apenas apreciable, salvo en la época de lluvia ${ }^{27}$. Pero a lo largo del tiempo ha tenido temibles avenidas ${ }^{28}$. El segundo punto de agua, lo constituyó la desaparecida fuente de la Rambleta ${ }^{29}$, aún recordada por personas de cierda edad de la población, y citada, entre otros, por A.J. Cavanilles ${ }^{30}$, en cuyo inicio se encontraba un antiguo manantial "la Font de l'Or». Además hay que contar con otros puntos de agua menores, que a causa de los movimientos del terreno y de una cierta desecación han ido desapareciendo. Bien el caso es que en el recinto las aguas eran abundantes, quizás en algunos momentos del año demasiado. En un establecimiento agrícola el disponer de agua era y es considerado de suma importancia, pues se ha de hacer uso de ella para múltiples menesteres. En los corrales habian de habilitarse pilones para que abrevaran los animales (bueyes, gansos, cerdos), y se bañaran cuando regresaran de los pastos (Varrón, r.r. I, XIII,3). Asimismo, y según los agrónomos, debía haber un estanque en el cual se remojaran los granos que necesitaren macerarse en el agua antes de ser empleados (Varrón, r.r. I, XIII,3; Columela, r.r. I, VI). Y, por supuesto, en toda villa romana de cierta altura existía un estanque-vivero para peces y aves acuáticas (Columela, r.r. VIII, I).

Tradicionalmente la población de Catarroja se dedicó a la pesca, con toda probabilidad al menos desde la Edad Media, efectuándose en las

\footnotetext{
27 El clima es tipo mediterráneo, con período invernal húmedo y verano cálido. Según datos recabados del Instituto Nacional de Meteorologia. Centro Meteorológico de Valencia las precipitaciones máximas se dan en otoño, y más concretamente en el mes de septiembre. Municipio de Catarroja: Precipitaciones totales mensuales: año 1996 , septiembre: $111.0 \mathrm{~mm}$. Año 1997, septiembre: $96.0 \mathrm{~mm}$. Precipitaciones máximas en 24 horas: año 1996 septiembre: $45.0 \mathrm{~mm}$. Año 1997, septiembre: $27.1 \mathrm{~mm}$. Primer día de la precipitación máxima: año 1996 , septiembre: 11.0 $\mathrm{mm}$. Año 1997, septiembre: $28.0 \mathrm{~mm}$. Los vientos dominantes son los del oeste y noroeste. provocando las lluvias el del suroeste

28 P. Llorens y Raga, La villa de Catarroja. Valencia, 1967. En nota 17, pág. 28, de su es tudio alude como catastróficas. a las avenidas de los años 1775, 1864, 1869, 1895, 1952 y 1357. No es dificil pensar que durante la época de poblamiento romano se darian similares avenidas, y más teniendo en cuenta que el clima, aunque siendo en esencia el mismo. era más riguroso en todos los aspectos.

24 Su nacimiento se halla situado al extremo occidental de la calle de San Antonio, cf. P LloREnS y RaGa, La villa de Catarroja, pág. 31.

30) Observaciones sobre la Historia Natural. Geogafia. Agricultura. Poblacion y Frutos del Reyno de Valencia, Madrid, 1795, pág. 169
} 
acequias y canales ${ }^{3 t}$. Consta textualmente, que en el siglo xvIII más de 450 familias pescaban en la Albufera ${ }^{32}$. Ahora bien, a pesar de que los habitantes de Catarroja vivieron, en parte, dedicados a la pesca, un cierto porcentaje se empleó en la agricultura, puesto que todo el territorio es llano, y el terreno fértil, siendo apto para el cultivo de grano, legumbres, hortalizas, frutales, vid, olivo.Con los datos que poseemos nos es posible deducir que los habitantes de la villa no se especializaron en la pesca, a lo largo de su dilatado funcionamiento, y a pesar de haber sido sometida a muy variados avatares, como nos los muestran los diversos reacondicionamientos del espacio constructivo. Lo cual no obsta para que una parte de las proteinas necesarias para su alimentación fueran extraidas de la Albufera. Pero entre la enorme cantidad de objetos recuperados no ha aparecido ninguno relacionado con esta actividad. $Y$ tampoco se encuentra residuos de pescados entre los restos óseos de mamiferos, aves, y conchas de moluscos gasterópodos, concretamente caracoles terrestres ${ }^{33}$. La falta de actividad pesquera parece extraña, pensando en la proximidad de la Albufera, mas hay que tener en cuenta, repetimos, que la investigación se ha llevado a cabo a nivel de prospección, es decir a través de pozos y zanjas de sondeo, para verificar, única y exclusivamente, la extensión del yacimiento, y en ningún momento se llegó a estratos estériles. Asi pues gran parte de la información ha quedado en reserva, contemplandose una futura excavación sistemática. Si, en cambio, se han hallado claros vestigios de una agricultura desarrollada y, al parecer, especializa$\mathrm{da}^{34}$. $Y$ entra dentro de lo posible, porque se han determinado numerosos restos óseos bóvidos y ovicápridos, que la actividad pecuaria también se contemplara en los planteamientos de esta unidad de producción, que tendería, como es bastante usual, a ser autosuficiente. Las pesas de telar son un argumento más a favor de la ganaderia: aprovechamiento y tratamiento de la lana.

31 Las principales especies son anguilas, barbos, carpas, tenques, etc,

3: A.J. Cavanitles, Observaciones sobre la Historia Natural..., pág 169. B. Espinal.t y Garcia, Atlante español.... págs. 200-201, incide sobre dicha cuestión, indicando que una tercera parte de sus vecinos son pescadores que pescan en la Albufera y que proveen de pescado no sólo al lugar sino a los inmediatos.

33 Los restos de fauna y malacofauna están siendo estudiados por el prof. Dr. A. MORALES, de laboratorio de Zooarqueologia del Departamento de Biologia, de la Facultad de Ciencias, de la Universidad Autónoma de Madrid, por ello no podemos definir aún con nitidez, salvo excepciones que reseñamos, la fauna que se encuentra en el asentamiento

${ }^{34}$ Según comunicación personal del Prof. C. Carreras, de la Universitat Oberta de Catalunya, miembro del equipo de investigación del Monte Testaccio. Estudia los recipientes cerámicos de almacenaje y transporte, como dolia, ánforas, orzas, ollas. No poseemos aún los resultados de su trabajo, aunque parece ser que hay una cierta especialidad en la viticultura. No obstante nos abstenemos de publicar nada provisional ni definitivo. 


\section{DESARROLLO INTERNO DE LA VILLA}

\section{IV.1. Conservación}

En la actualidad la partida de Salt del Llop, y concretamente el lugar en el que se halla situado el asentamiento, es un área de abancalamientos, donde se cultivan productos hortofrutículas. Esto ha condicionado de modo decisivo la situación precaria en que se han encontrado las estructuras. Ha de contemplarse la posibilidad de que en distintas zonas, aquéllas hayan sido afectadas por la vertedera de los arados modernos, por el movimiento de tierra, por la extracción de la misma para rajolares (fábricas de ladrillos), y por la recogida sistemática de piedra. De hecho y en relación con este último extremo, vecinos de Catarroja nos comunicaron que de l'Hort de Pepica y alrededores, se desenterraron en tiempos pasado sillares de distinto tamaño, algunos de ellos de buena talla. Aún documentamos sillares reutilizados, tegulae, imbrices y ladrillos en la construcción de acequias y casetas cercanas al yacimiento. Los sillares, bien escuadrados, con las dimensiones medias siguientes: $0,80 \mathrm{~m}$. de largo $\times 0,50 \mathrm{~m}$. de alto $\times 0,60 \mathrm{~m}$. grosor, muestran la riqueza constructiva que debía tener el yacimiento en la fase altoimperial ${ }^{35}$. Este tipo de mampostería es, en efecto, frecuente en ámbitos urbanos, fundamentalmente edificios públicos, religiosos o privados nobles.

De todas maneras, aunque el asentamiento no hubiera sido expoliado a través de los siglos, se hace necesario contar con el paso del tiempo, destructor natural. La erosión ha actuado intensamente sobre el yacimiento. $Y$ además hay que tener presente que la tierra de base, bajo las capas de humus y cultivable más oxigenada y abonada, consiste en una arcilla muy compacta, que es altamente corrosiva para el material orgánico. Concretamente el estudio del esqueleto humano descubierto en el denominado, según metodología de trabajo, enterramiento II, supuso una intensa tarea, a consecuencia de hallarse en pésimo estado de preservación - pérdida considerable de tejido óseo-, al estar inmerso en la arcilla ${ }^{36}$.

Serían los rasgos desaparecidos, fabricados en parte con madera, los que, tras un pequeño inciso acerca de la misma ${ }^{37}$, enumeramos. Sobre la

Con el movimiento de tierras, consecuente con la puesta en marcha del Plan Parcial P.A.U 2. Chimenea. se destruyeron acequias, y de las mismas recuperamos e inventariamos varios sillares de las caracteristicas aludidas en el texto

Estudio realizado por la Dra. C. SAMPEDRO, del Laboratorio de Arqueozoologia de la Facultad de Ciencias. de la Universidad Autónoma de Madrid.

Vitruvio (II, IX) diserta largamente sobre las diferentes maderas utiliadas en carpinteria. 
madera, tan popular y utilizada en todas las latitudes donde existe, se ha de indicar que en la zona de investigación no debió ser excesivamente empleada. $Y$ si lo fue se debió conseguir en otros parajes, puesto que no es un área particularmente forestal, ya que la tierra es tan rica que la agricultura pudo explotarla en su totalidad. De manera que la madera, para aliviar el trabajo de transportarla de allí donde se encontrara, en algunos casos sería sustituida, sobre todo para levantar paredes, por otros componentes, como el adobe, el opus latericium de Vitruvio (II, III). Se ha hallado muy frecuentemente en excavación. $Y$ la materia prima para su elaboración era muy fácil de obtener. Para las techumbres se pudieron emplear vegetales en forma de haces. En ambos casos para áreas de servicio.

Retomando el tema que nos ocupa, acerca de la desaparición de rasgos y enseres, serian éstos y otros ${ }^{38}$ que obviamos, por necesidades de espacio:

1. Cobertizos varios, horrea, cuadras, graneros, porquerizas, tablazón de los pisos, armaduras de cubierta, ventanas, contraventanas, puertas. De estás últimas sólo quedan fragmentos de piezas metálicas, barras, anillas, cerraduras y gruesos clavos de hierro y bronce que ornamentaban la cara externa de las hojas. En relación con las puertas, el umbral de un acceso fue encontrado en el transcurso de la excavación, reutilizado, calzado con fagmentos de tegulae y cascajo de piedra, en el alzado de un muro posterior, (segunda fase, tardoimperial). Se trata de un sillar tallado, fragmentado, con dos marcas de pinza, y cuya cara superior, gastada por un tránsito continuado, posee una profunda incisión semicircular, resultante de la fricción de una barra vertical de cierre, componente de la puerta. Otro sillar de las mismas características estructurales y formales, pero sin marca alguna, se halló junto al primero, asimismo formando parte del muro aludido.

2. Toda clase de contenedores y artilugios para las diferentes faenas agricolas, como cestos, canastos, espuertas, serones, cuévanos, coladores, que se pueden hacer con juncos, mimbres, cañas, esparto, o con otros vegetales; o los que se tejen con cañamo, lino, junco, esparto, tales como sogas, cuerdas, redes. O los que se fabrican con madera, mangos de las diversas herramientas con las que trabajaban el campesino, el carpintero, el herrero, el alfarero, el curtidor, etc.: horcas, escardillos, azadas, azuelas, podaderas, navajas, hoces, palas, rastrillos, navajas, hachas.

38 Si nos atenemos a los textos de los agrónomos y, en parte, a nuestra experiencia e investigación 
3. Pértigas para apoyar las viñas, cubas para contener el vino, escaleras, cubos, duernas, parihuelas para el estiércol, odres de cuero.

4. Armazones de carros. Al respecto de estos vehículos, en los documentos examinados, arqueológicos o textuales, pueden contemplarse carros de uno o dos trenes de ruedas, radiadas o macizas, tirados por mulos, asnos o bueyes uncidos, acarreando la cosecha recolectada, o cualquier otro género transportable y/o comerciable. Los carros más utilizados en el ámbito rural fueron el carrus y el plaustrum. El carrus comprendía dos trenes de ruedas radiadas, aunque hay excepciones ${ }^{39}$ (por algunos autores es denominado plaustrum maius). El plaustrum era el clásico carro propio del ámbito rural, aunque no es descartable su utilización, secundariamente, en muy diversos campos de la vida cotidiana civil y militar, como se documenta en los relieves de las columnas Trajana y Antonina ${ }^{40}$. Se empleó en Roma y en la mayor parte de las provincias del Imperio, lo cual es apreciable en la musivaria, la pintura y el relieve. Tenía un tren de ruedas, éstas de madera maciza, y era movido por bueyes, pero también lo pudo ser, menos común, por mulos y asnos. Su estructura formal era muy semejante a la de los carros empleados en el oeste asturiano hasta la década de los años sesenta.

5. Máquinas para trillar. Varrón (r.r. I, LII, 1) describe dos variedades. La primera, que denomina tribulum, es el trillo clásico, que aún puede verse en Castilla, formado por dos tablas juntas con piedrecillas de filo cortante - silex o cuarcita-, en la cara inferior. La segunda, la denominada plostellum poenicum, consistía en una máquina con ruedas, con hierros para triturar la mies. De origen cartaginés, se empleaba en la provincia Citerior. Yugos para uncir a los animales de tiro ${ }^{41}$. Arados.

6. Toda clase de útiles para amueblar y vestir los aposentos, telares, etc.

\section{Vestidos, calzados.}

Los componentes metálicos de lo especificado, paulatinamente pudieron ir corroyéndose, hasta descomponerser, sobre todo si eran piezas de pequeñas dimensiones. A pesar de esta afirmación, contamos en el inventario arqueológico con restos de hierro pero en general informes, salvo múltiples clavos de tamaños diversos. Otros elementos metálicos los aprovecharian las familias godas y árabes, que sucedieron a las romanas. Es muy posible que los grupos visigodos, que generalmente se asentaron en zonas

\footnotetext{
M.P. Garcia-Gelabefit, El carro como transporte agricola .... págs. 530-532 M.P. Garcia-Gelabert, El carro como transporte agricola ... págs. 532-535.

M.P. Garcia-Gelabert. El carro como transporte agricola... págs. 535054
} 
rurales, vivieran en las estructuras de la antigua villa. $Y$ acondicionaron el espacio y tal vez construyeron alguna nueva estancia, de las que quedan señales muy difusas. Esta falta de información no es de extrañar, porque al encontrarse en los estratos más altos las construcciones desaparecieron, arrasadas por la vertedera de los arados, o por la tónica que se da en l'Horta, el continuo movimiento de tierras. No obstante se encuentra en la "colección particular» de un destacado furtivo de Catarroja, un bloque de piedra decorado con motivos posiblemente de filiación goda. El respecto de esta plaga endémica para la Arqueología constituida por los excavadores clandestinos, no queremos dejar de mencionar la nefasta labor llevada a cabo por el individuo aludido, que se ha encargado de "prospectar» intensiva y extensivamente desde hace años la superficie del yacimiento. Consecuentemente ha hecho desaparecer valiosos vestigios (artefactos muy variados), que, de haberse hallado in situ, podrian habernos tacilitado enormemente la labor para delimitar en superficie el yacimiento, conforme a la línea de los científicos I. Hodder y C. Orton ${ }^{42}$, que seguimos.

En cuanto a los musulmanes que se establecieron en la zona, concorde con su sistema de poblamiento rural, en alquerias (vid. nota 1), también es posible que, o bien se adueñaran de las antiguas edificaciones, expulsando a los visigodos, - no hallamos huellas arquitectónicas con su impronta-, o simplemente cultivaran las tierras que antaño pertenecieran a los domini de la villa, ya roturadas desde la antigüedad. En este caso, frecuentarian el lugar, apoderándose del material de construcción, y de cualquier enser que aún quedara.

\section{IV.2. Interpretación de las construcciones, efectos muebles y ambientes funerarios}

En el espacio estudiado, se pueden delimitar y definir: un ámbito productivo, la pars rustica, que correspondería a actividades agrícolas, ganaderas, etc.; un ambito residencial, la pars urbana, al suroeste del primero; y un/os ámbito/s funerario/s, al sur del residencial.

¿Pars urbana, pars rustica. ¿Prioridad de una con respecto a la otra? ¿Sencillamente una villa rústica, con una vivienda cómoda para uso del propietario? Son múltiples los interrogantes y la base de apoyo es muy frágil. Pero eso sí, la villa, sea cualesquiera su funcionalidad, por los indi-

42. Análisis espacial en Arqueologia, Barcelona, 1990, passim, y especialmente págs. 27-40. 
cios rústica, se levantó en el medio campesino, no lejos del asentamiento de Valentia.

Y la civilización es romana (dejando al margen los reacondicionamientos visigodo y tal vez árabe), de eso no hay duda, la evidencia es fuerte. Es observable en la arquitectura, y en el instrumental mueble de diferente tipología. Pero ¿de quién fue propiedad el hábitat?, ¿de itálicos, de romanos, de indigenas romanizados?, no sabemos. Tal vez haya que descartar a estos últimos (como propietarios, no como fuerza de trabajo), teniendo en cuenta, que por lo menos para los primeros años de existencia del núcleo habitacional, los hispanos no se hallaban aún en condiciones, como pueblo sometido, ni de poseer tierras, como las que con toda probabilidad comprendía el asentamiento, ni de haberse aculturado tan profundamente. Efectivamente todos los materiales son de corte romano, excepto algunas vasijas de mediano tamaño, cuyas superficies exteriores fueron decoradas con motivos geométricos pintados, siguiendo la tradición ibérica, y algún que otro fragmento atípico, perteneciente a las civilizaciones visigoda y arabe. Los recipientes de barro son muy diversos en cuanto a formas, tamaños y calidades, pero en oposición prima una notable uniformidad en cuanto a su funcionalidad. Hay un alto porcentaje de cacharros para guardar grano y/o aceite y/o vino; para guardar viandas para el consumo del año; para guardar las conservas que suelen elaborarse en las granjas durante el otoño y el invierno. Son los dolia, tinajillas, ánforas vinarias y olearias, ollas con/sin asas, orzas, lebrillos, platos, tapaderas para algunos de estos recipientes. $Y$ no hay que perder de vista el menaje cotidiano doméstico y de cocina, hallado en gran número: platos, vasos, ollas, cazuelas, jarros, morteros. También son numerosas las lamparillas -lucernas -, para alumbrar las estancias. En cambio no es abundante la vajilla de lujo (fundamentalmente de TSH y africana), hay escasez, y desde luego nunca se encuentra en la pars rustica, sino en pequeña cantidad en la pars urbana y, sobre todo en un basurero localizado al sur de la pars urbana, entre ésta y las tumbas.

Por las especiales características de la investigación no ha habido posibilidad de completar cuadros cronológicos ni estratigráficos ${ }^{43}$. Así pues quedan por resolver importantes incógnitas para la real interpretación de los rasgos arquitectónicos. Insistimos en que la nota característica del yacimiento es su estado de devastación, que no hemos hallado en ninguno

43 Contamos con la datación aportada por la numismática, pero debe completarse con la que aportará el estudio cerámico, aún en curso. Por ello nos abstenemos de precısar fechas, que podrian variar, aunque no sustancialmente. 
de los que hemos excavado con anterioridad. Pero estamos en situación de poder precisar que existieron unas considerables construcciones en dos momentos edificadores (épocas de los antoninos y tardoimperial), sin que pueda excluirse una ocupación más temprana. Posteriormente hay sucesivas organizaciones del espacio en los últimos tiempos romanos de la villa, con construcciones muy mediocres, a base de mampostería de sillarejo sin solidez, amalgamado someramente con arcilla ${ }^{44}$. $Y$ finalmente una ocupación visigoda, destacable por la extremada vulnerabilidad de la mampostería. Por cierto, una nota a tener en cuenta es que ninguno de los muros aislados, salvo excepciones cimientos, tanto de la pars rustica como de la urbana, se alza sobre fosa de cimentación.

El plano general de la villa responde a un esquema en $U$, con una orientación claramente definida norte-sur. Y parece tratarse de una villa de planta diseminada, en la cual las edificaciones rústicas se dejan ver dispersas, sin formar bloque con la pars urbana ${ }^{45}$. $Y$ es muy posible que tanto al este como al oeste se acondicionaran amplios espacios para corrales, eras, cuadras, cobertizos, que se encontrarian vallados ${ }^{46}$, aunque el cerramiento si era de seto vivo no se conservó ${ }^{47}$. Desde luego hacia el este, extramuros del conjunto arquitectónico, existe un área, cuyas dimensiones no nos es posible determinar en el estado actual de la investigación, pavimentada a base de guijarrillos rodados, que indudablemente, corresponde a un espacio abierto de servicios -corrales, eras $-{ }^{48}$. Y en el extremo sur de este espacio se encontró un estrato de tierra cenicienta y suave, con restos vegetales carbonizados, que aportó fragmentos de lucernas, TSH y africana, cerámica de pare-

\footnotetext{
4.4 Según los estudios del Prof. P.P. Ripolles. del Departamento de Arqueologia y Prehistoria de la Facultad de Geografia e Historia de la Universidad de Valencia, y de D. TOMAS HurTADO, estudiante de la Universidad de Valencia, la moneda más antigua hallada en el proceso de excavación es un dupondio de Emerita?, fechado entre los años 23-2 a.C., y la más moderna un nummus de Constantino, cuya fecha es la de 308-309. P. LloRens y Raga en su obra La villa de Catarroja. págs. 38-43, escribe que logró recuperar trece monedas, que fueron estudiadas por $P$. Beltrán, las cuales aportaron una cronologia desde la República (un as). a un pequeño bronce de Constantino II, datado en el gobierno de Constantino.

* N. Moriere, Estructuras rusticas de las "villae" en la Galia Narbonense, J. Mangas. J. Alvar (eds.). Homenaje a José Mo Blázquez. III. Historia de Roma. Madrid. 1993. pág. 174.

to Contemplamos, como complemento a las campañas de estudio desarrolladas, prospecciones geofísicas.

4? Varrón (r.r. I. XIV,1) alude a cuatro tipos de cercas: natural. campestre, militar, artificial También Columena (r.r. XI, III), en su caso, a setos vivos en los huertos.

t. Para eras Columela (r.,. I. VI): “...La mejor es la que está empedrada con guijarros...". Para corrales: Varrón (r.r. XII, I, 2): “...En el corral deben tenerse grandes espacios cubiertos para meter los carros y las demás herramientas, a fin de resguardarlas de los daños de la lluvia del cielo...". Y en XII, I, 3: “...En las grandes fincas hay que disponer de dos corrales...".
} 
des finas y de cocina, huesos de animales (ovicápridos) y conchas de caracoles terrestres. El estrato se extendia alrededor de 30 metros cuadrados (la potencia la desconocemos). La riqueza del mismo hizo que pensáramos en la posibilidad de que se tratase de un basurero, que con relación a la zona empedrada, bien una era, bien un corral, se hallaría en el límite exterior.

\section{IV.2.1. Pars rustica}

Los vestigios son inequivocos: materiales de construcción perecederos, de los que aún quedan restos de vigas de madera. Mampostería en seco. Suelos de tierra apisonada, limpia o mezclada con piedras, guijarros y cal. Paredes de adobe (figura 1).

Un área de este entorno comprende un suelo de cal y piedras, bordeando un horno excavado en la tierra. Caracteriza un sector de fundición,señalado por enorme cantidad de escorias de hierro.

Dos más son los hornos, alfares, recuperados. Ambos de planta circular, cuya superficie interna es de piedra, recubierta al exterior con una

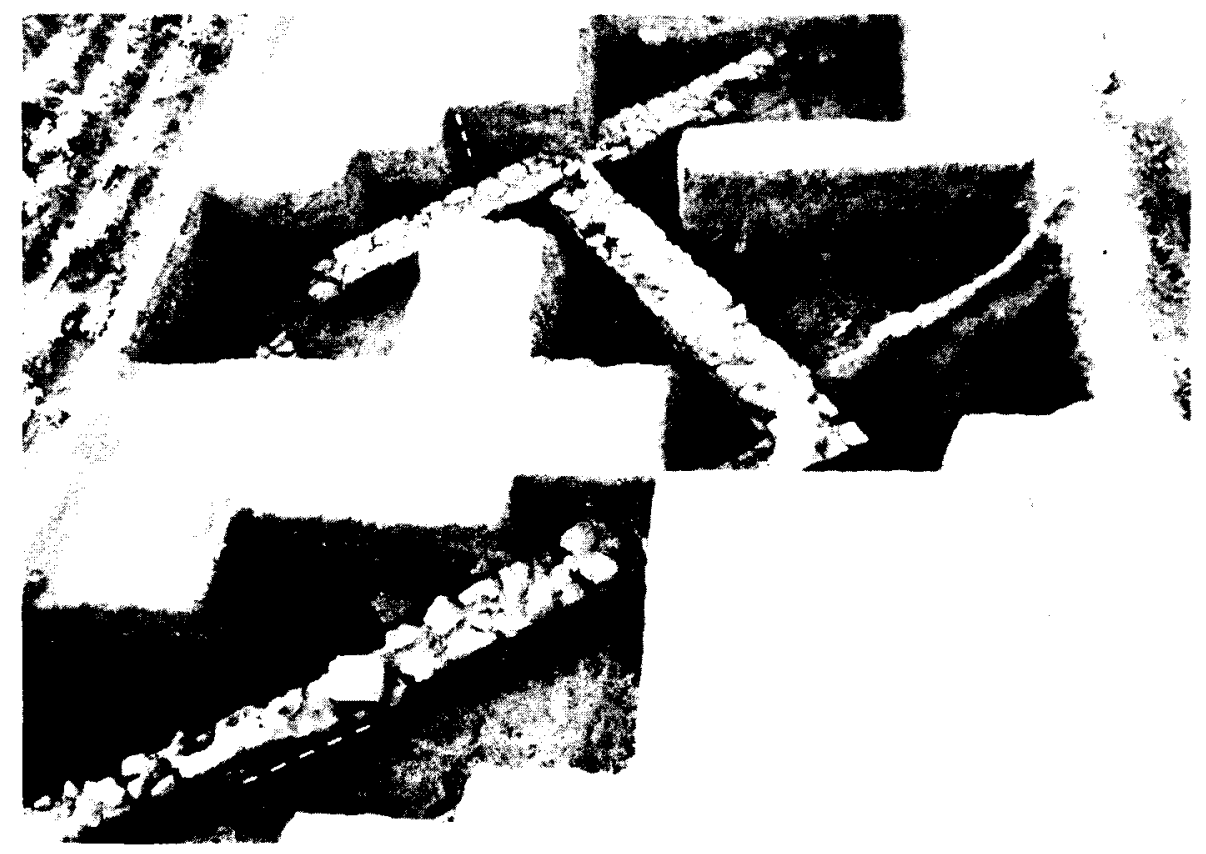

Figura 1. Pars rustica. Vista parcial. 
gruesa capa de arcilla, que consecuente con el calor de la combustión se endureció. Uno de ellos, está aislado, al suroeste del conjunto habitacional, tal como indican los expertos latinos debe ser para evitar incendios y malos olores (Vitruvio VI, IX). En cambio el otro (figura 2), al noreste, se halló muy cercano a una retícula de habitaciones, cuyos muros están construidos con mampostería (mampuestos de talla informe, o cantos rodados) amalgamada con arcilla. Asimismo se aisló una estructura rectangular dividida en pequeñas salas, construida pobremente en materiales perecederos (ha sido recogido algún fragmento de viga) y sillarejos, no habiéndose hallado vestigios de materias aglutinantes entre ellos. El suelo es de tierra batida.

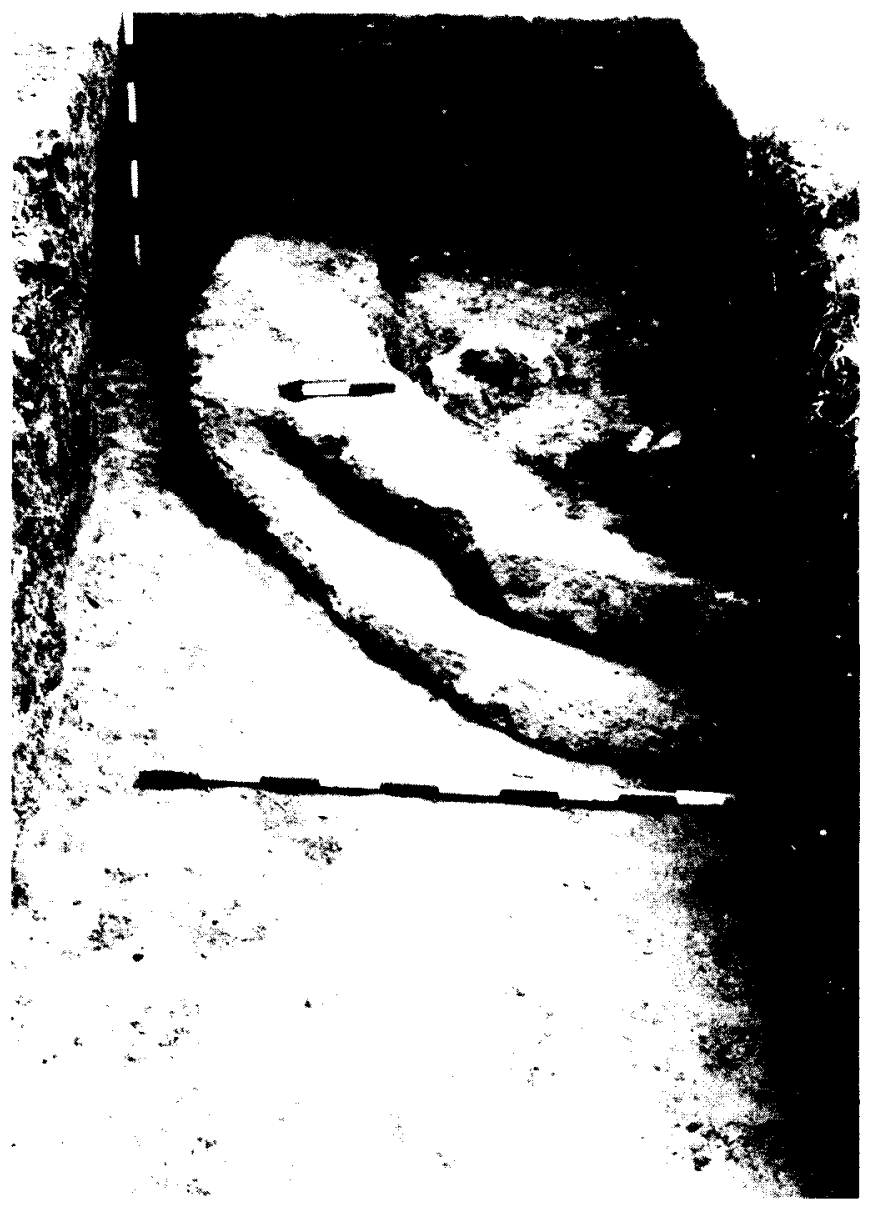

Figura 2. Alfar. 
Los telares, como indicamos supra, se hallan documentados por la aparición de pesas de arcilla, indicativas de labores textiles, imprescindibles en las villae.

En una estancia cercana a las descritas se aislaron cuatro dolia enterrados en el suelo (figura 3). Los bordes se habian dispersado, formando un derrumbe en derredor, uno de ellos ostentaba un VIII (figura 4). Asociados a estos recipientes se hallaron vasijas menores (aludidas supra) con similar función, muy fragmentadas. La abundancia de estos recipientes nos hace afirmar que esta habitación se dedicó a almacén de productos agrícolas, o de sus derivados, bien para el consumo diario, bien para el comercio.

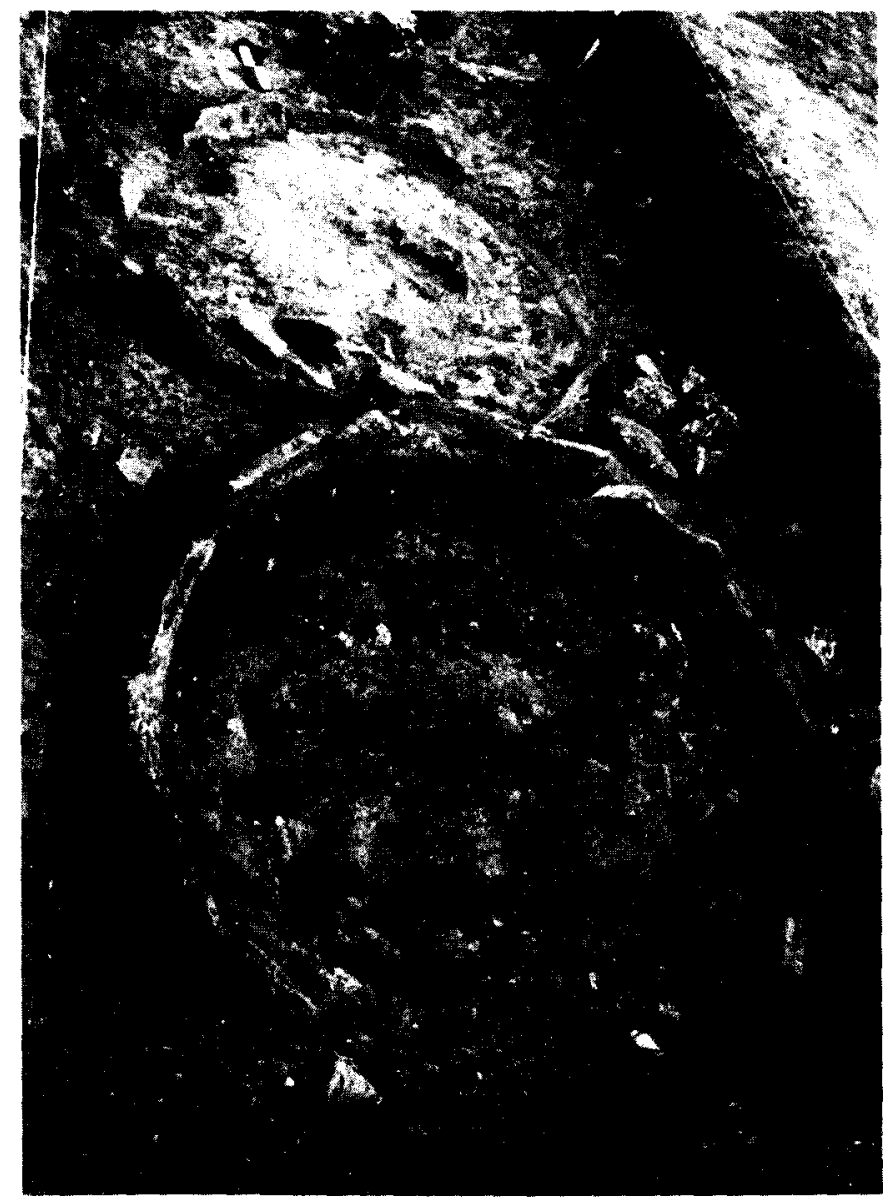

Figura 3. Almacén con dolia. Vista parcial. 


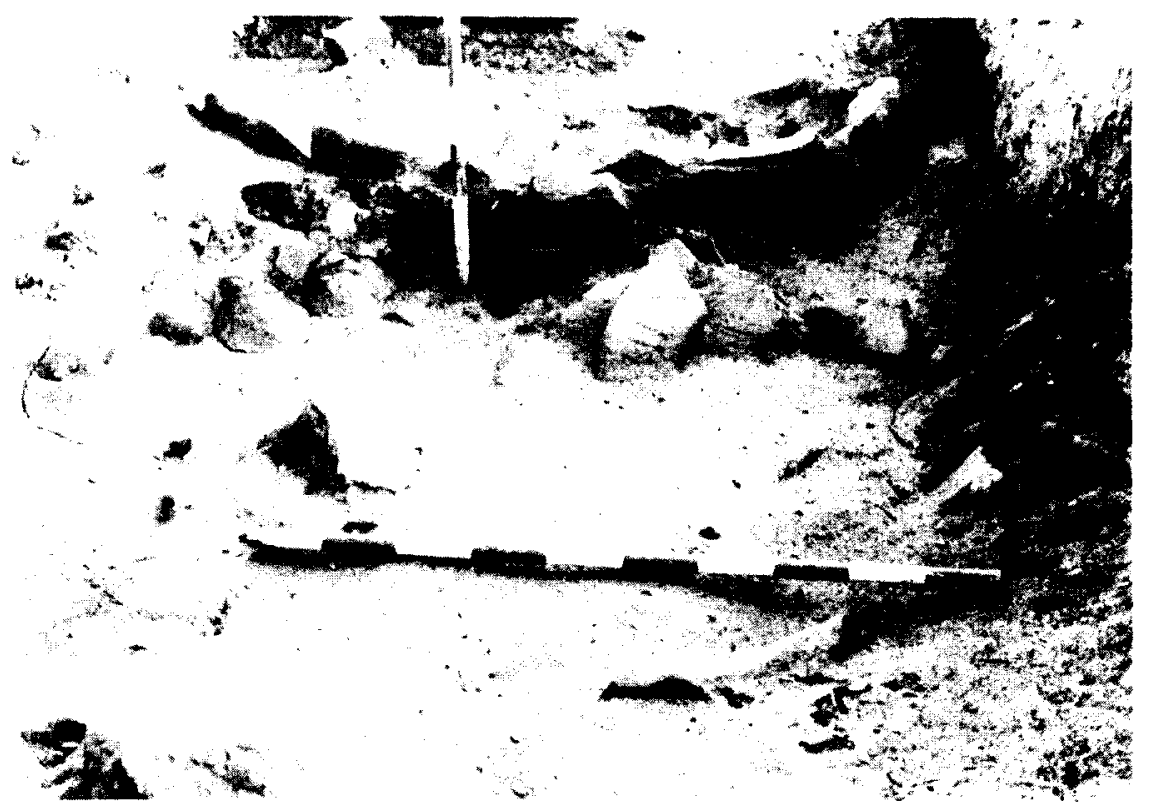

Figura 4. Detalle. con numeración (VIII), de dolium.

\section{IV.2.2. Pars urbana}

Es un sector que contrasta ampliamente con los restos descritos anteriormente.Ya achacaba Varrón (r.r. I, XII,7) en el siglo I a.C. que los dueños de las fincas trataban de construir su morada lo más amplia y elegante posible, imitando el lujo de las de la ciudad, olvidando en cierto modo la parte más práctica y racional, que era atender a las necesidades de la hacienda (salud de los animales domésticos y conservación de las cosechas). La arquitectura aqui es de piedra con labor tosca o sillares, ligada con mortero de cal. Las techumbres se componen de tegulae y elementos de estanqueidad de los empalmes, los imbrices o cubrejuntas. Algunos pavimentos son de opus reticulatum. Las paredes de las estancias están estucadas (pigmento de origen mineral: almagre ${ }^{49}$ ). Un muro rectilíneo, revestido de barro en el exterior, con restos importantes de mortero hidráulico en la parte inferior y en el suelo, define una estructura impermeable, con un objetivo probable de alma-

14. En las proximidades del asentamiento de l'Hort de Pepica debieron existir almagreras (actualmente, al haberse desvirtuado el paisaje no es posible hallarlas), suficientes para el avituallamiento de una cierta cantidad anual de almagre. Los yacimientos de este tipo. muy populares en numerosos terrenos de diferentes calidades, no son nunca minas subterráneas. sino afloramientos. 
cenamiento de agua de lluvia. La misma, como escribe Paladio (Op. agric. I, XVI; I, XVII,4) es la mejor de todas para beber, sobre todo en las zonas (como la estudiada) sospechosas de enfermedades estivales. Estas cisternas se encontraban en la pars urbana, junto al hábitat propiamente dicho.

En un sondeo ubicado próximo a la cisterna, al oeste, que confirma el sector residencial, se halló un importante derrumbe de restos constructivos de excelente calidad, tales como sillares de tamaño mediano, parte de la cubierta con tegulae e imbrices, algunas enteras, clavos para las vigas. Mezclados con el derrumbe había vasijas de TSH y africana, estuco (pigmento almagre) y pequeñas piezas de ladrillo en forma de rombos, para formar pavimentos de opus reticulatum, generalizando, el opus testaceum de Vitruvio (II, III). Al suroeste se halla todo un conjunto de muros de 0,50 a $0,65 \mathrm{~m}$. de ancho. Algunos conservan la primera hilada de sillares, otros se encuentran a nivel de cimentación y, en general, muestran la importancia de este sector. Los contrafuertes de dicha planimetría corroboran to cuidado de esta parte. $Y$ es probable que la morada residencial contara con baños privados. Estos baños pequeños, muy usuales en las villae no demasiado extensas, estaban compuestos de dos estancias, tepidarium y caldarium. Signos de la presencia de las mismas podian ser los varios tubili hallados. Y un ambiente, del que no conocemos el pavimento, cuyas paredes están fabricadas con opus caementicium (figura 5), con enlucido

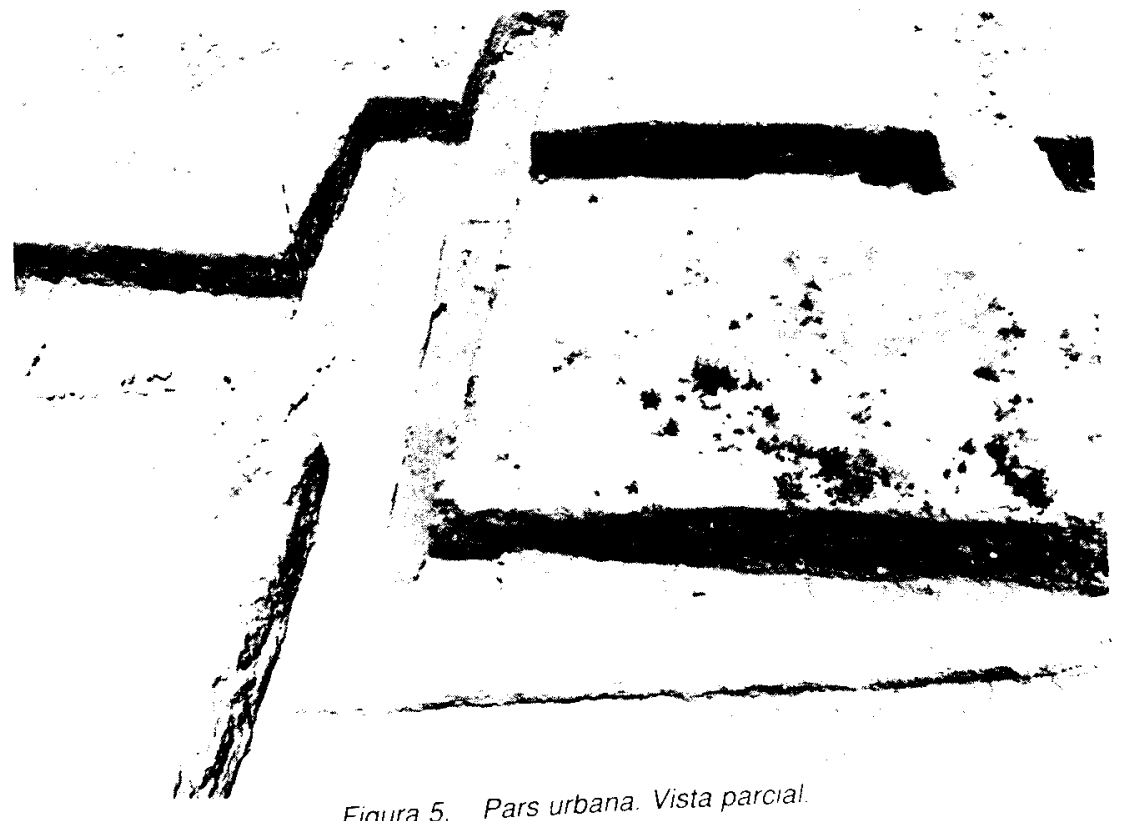

Figura 5. Pars urbana. Vista parcial 
al interior de hormigón hidráulico. Al sur del posible baño, a medio camino de los enterramientos, se halló otro basurero, en el que fueron encontrados valiosos materiales muebles como vajilla de TSH y africana ${ }^{50}$, recipientes de vidrio, cuentas de pasta vitrea, lucernas, asas de bronce con decoración figurada, pertenecientes a jarras o tazas, anillos, pomos para afeites, monedas, aunque éstas consisten en moneda de uso para transacciones de escaso valor, propias de una sociedad rural.

\section{IV.3.3. Ámbito funerario}

Los enterramientos ${ }^{51}$, se sitúan en la parte sur del hábitat, desplazados aproximadamente 200 metros ${ }^{52}$. Fueron encontradas dos tumbas, separadas entre si por $3 \mathrm{~m}$. de distancia. La superestructura funeraria de ambas se compone de tegulae a doble vertiente, rematadas por imbrices. La unión entre las tegulae se selló con cal sobre la que se habían colocado imbrices y fragmentos de cerámica. Resultaron, pues, unas superestructuras muy compactas. La ausencia de ajuares, así como la tipología de las superestructuras hace suponer que nos encontramos ante enterramientos tardoimperiales, datados en algún momento del siglo IV. Es decir, asociados con la segunda fase del yacimiento.

De la tumba I, que poseía una orientación este-oeste, se conservó la mitad de la superestructura. $Y$ salvo ocho clavos de hierro, de cabeza re-

50 Los recipientes de terra sigilla están siendo estudiados por el Dr. Santiago Prado.

5t Ambos enterramientos fueron excavados sistemáticamente, y con posterioridad a su documentación se retiraron. Se debió esta actuación extraordinaria a que se encontraban, lógicamente extramuros del ámbito habitacional, pero también constituian rasgos culturales aislados, no comprendidos dentro de la zona que se dejó en reserva para conservar el yacimiento. Antes de ser retiradas, se numeraron todas las piezas de las superestructuras, para reconstruirlas en el museo. cuya creación se contempla por las autoridades municipales de Catarroja.

52 Las necrópolis en las que fueron depositados los fallecidos en la villa, durante el tiempo en que se halló en funcionamiento, se encuentran, una al sur de aquélla, la otra pudo encontrarse al norte. Ambas a una distancia de respeto de la misma. Nos basamos para afirmar tal cuestión, en primer lugar en que en la zona sur, hallamos dos enterramientos, que describimos en el texto, y en la transmisión oral. Al respecto de ella, se nos comentó por vecinos de Catarroja, que antiguos propietarios de l'Hort de Pepica, levantaron tumbas en el área sur. Y en cuanto al área norte, en la actualidad es absolutamente imposible pensar que ahora se podria encontrar ningún indicio funerario, porque se extrajo, a través del tiempo, un volumen muy considerable de arcilla para atender a las necesidades de las fábricas de ladrillos. Posteriormente las canteras se rellenaron de escombros procedentes de la población. No obstante la tradición oral, en el caso del área norte no demasiado fidedigna, también ubicó alli enterramientos, lo que no podemos saber es de qué época. $Y$ en la zona oeste, asimismo a una distancia de respeto, por comunicación personal, un testigo presencial fiable nos informó que en su niñez se habia extraido en su huerto, en el que ahora hay una plantación de naranjos, un cadáver que yacia en posición vertical, bajo una losa. 
donda, no contenía nada más. Por tanto se trataba de un enterramiento cenotáfico ${ }^{53}$, porque la tumba no fue violada.

La tumba II (figura 6), orientada claramente en dirección norte-sur, y situada al sur de la primera, tenía la misma superestructura, aunque ésta conservada intacta. En el interior se halló el esqueleto de un varón robusto, de edad madura (más 45 años). Yacía decubito supino con la cabeza,

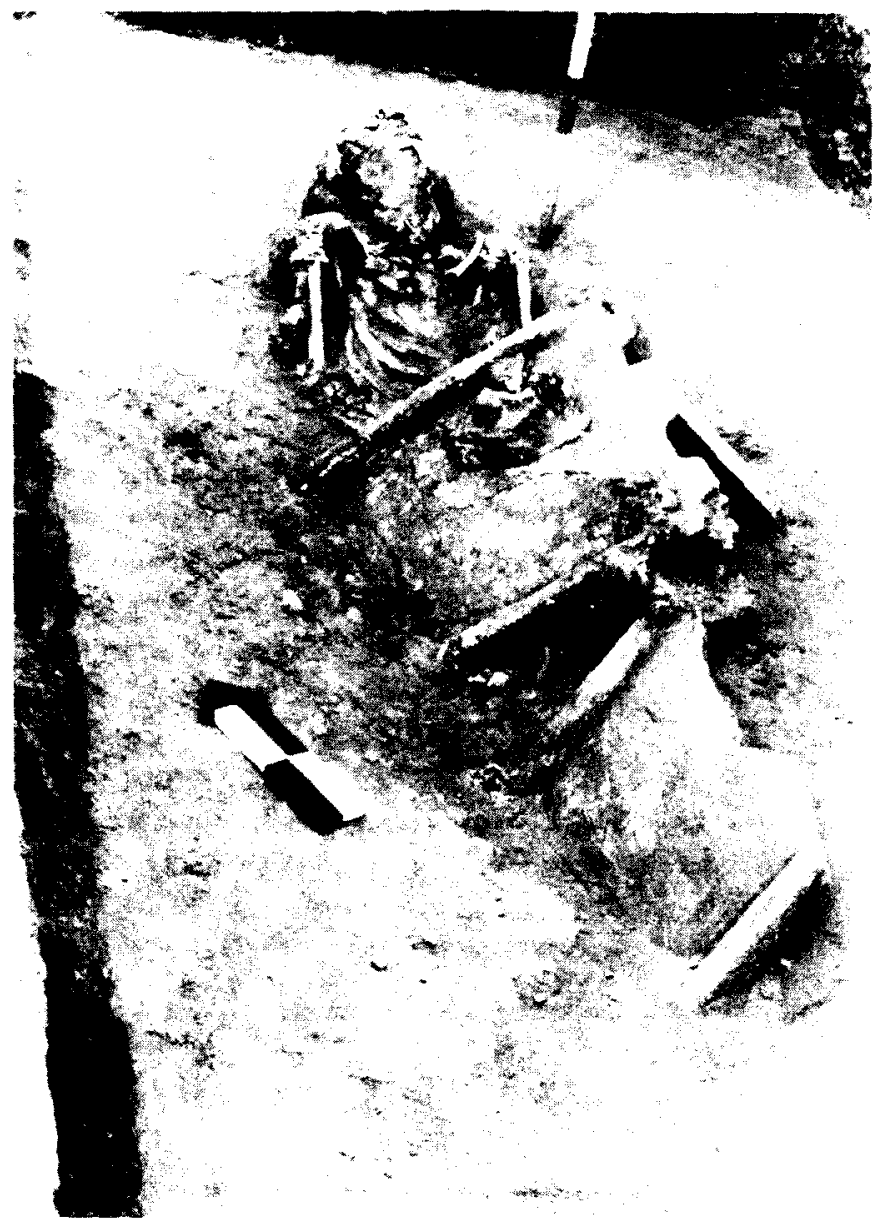

Figura 6. Tumba II.

53 M.P. Garcia-Gelabert. M. Gafcia Diez, La religión en el mundo ibérico. Enterramientos cenotáticos, Espacios y lugares cultuales en el mundo ibérico. vol. 18 Quaderns de Prehistória i Arqueologia de Castello, 1997, págs. 405-416 
girada ligeramente hacia el oeste, descansando más alta que el resto del cuerpo, colocada sobre un ladrillo, éste de canto. Los brazos aparecian semiflexionados, con las manos juntas sobre la cadera. Los pies tenían los talones muy juntos. Probablemente para ser enterrado fue envuelto en un sudario recio. La arcilla que lo cubria contenía numerosos nódulos de carbón y cal. Parece que fue depositado sobre un lecho de ramaje, que cedió al descomponerse, envolviendo los restos óseos. Estudiado el cadáver se pudieron apreciar ciertas alteraciones en las vértebras de la zona cervical, que siguen el patrón de deterioro habitual en personas de edad madura en sociedades antiguas, asi como caries en los molares, y cabe la posibilidad de que sufriera periodintitis ${ }^{54}$. Diciembre, 1997.

i.i C. SAMpedro, Estudio de los restos humanos hallados en los enterramientos de Catarroja (en prensa).

NOTA: Los licenciados y alumnos de la Facultad de Geogratia e Historia, de la Universidad de Valencia que a continuación se indican, han colaborado activamente en que la excavación y los trabajos de labotarorio se hagan realidad: Jose Antonio Cuervas, Marta Dolz, David Hernandez. Francisco Javier Hernández. Tomás Hurtado. Luisa Martinez. Sonia Molina, Isabel Ramirez. M." Asunción Ramón. Luis Sánchez, José Vicente Sendra y Julian Talavera. Asimismo otros han colaborado esporádicamente en diversas actividades. Todos son artifices. junto con los firmantes de que la investigación de la villa de Castarroja fructifique. 